\title{
Bulanık VIKOR Yöntemini Kullanarak Proje Seçim Sürecinin İncelenmesi
}

\author{
Analysis of Project Selection Process Applying with \\ Fuzzy VIKOR Method
}

\author{
Yrd. Doç. Dr. Ayşe Yıldız
}

\begin{abstract}
Öz
Proje seçimi, karlllik, büyüme ve artan küresel rekabet ortamında işletmelerin hayatta kalması için verilmesi gereken çok önemli bir karardır. Ancak bu tür kararlar maddi ve maddi olmayan birçok faktör ve birden fazla karar verici içerdiğgi için genellikle karmaşıktır. Çok kriterli karar verme (ÇKKV) yaklaşımı bu gibi durumlarda kullanılmak üzere geliştirilmiş bir modelleme ve uygulama aracıdır. Ayrıca, bu seçim kararında kriter ă̆ırlikları ve alternatiflerin derecelendirilmesi çoğu zaman kesin ifadelerden ziyade düşük, orta, yüksek gibi dilsel ifadelerle değerlendirilmektedir. Bulanık mantık teorisiyle birlikte ÇKKV yöntemleri birçok kritik kararda bu gereksinimleri karşılamak için kullanılabilir. Bu çalışma da bulanı ÇKKV tekniklerinden olan VIKOR yöntemini kullanarak bir firma için en iyi projenin seçimi karar verme sürecini açıklamıştır.
\end{abstract}

Anahtar Kelimeler: Bulanık Mantık, Bulanık VIKOR, Proje Seçimi

\section{Abstract}

Project selection is very important making decision for the profitability, growth, and the survival of the establishments in an increasingly competitive global scenario. However, because of including many tangible and intangible factors and more than one decision makers these decisions are often complex. Multiple criteria decision making (MCDM) approach is a modeling and methodological tool for applying like these situtations. Also, in this decision the ratings of alternatives and the weights of the selection criteria often may be evaluated linguistic assessment such as low, medium and high
\end{abstract}

rather than certain expressions. An application of the fuzzy set theory along with MCDM methods have been used to make these requirements available for many critical decisions. This study explains decision making process using fuzzy VIKOR which is fuzzy MCDM method to choose the best project for the firm.

Keywords: Fuzzy Logic, Fuzzy VIKOR, Project Selection

\section{Giriş}

Her organizasyon artan küresel rekabet ortaminda kar elde etme, büyüme, gelişme ve gelecekteki faaliyetleri için sürekli yatırım yapmak ve proje geliştirmek zorundadır. Ancak işletmenin sahip olduğu fiziki, mali ve insan gücü kaynakları kıt ve sınırlı olduğu için bu kaynakların doğru alanlarda ve projelerde değerlendirilmesi işletmenin rekabetçi pozisyonunu koruması açısından kritik öneme sahiptir. Uygun projenin seçilmemesi durumunda iki olumsuz durumla karşılaşmak sözkonusudur. Birincisi daha uygun projenin seçilmesi durumda elde edilecek faydanın kaybı ve ikincisi ise uygun olmayan projelere kaynakların harcanmasıdır (Fouladgar ve diğerleri, 2011). Bu nedenle bir projenin uygunluğunun değerinin tahmin edilerek değerlendirilmesi işletmeler için oldukça önemlidir. Ancak proje seçim süreci birden fazla karar vericinin dahil olduğu, farklı ölçümlerle ifade edilen birden fazla ve birbirleriyle çelişkili nicel ve nitel kriterlerin sözkonusu olduğu karmaşı bir süreçtir.

Yrd. Doç. Dr. Ayşe Yıldız, Gazi Üniversitesi İİBF İşletme Bölümü, ayseyildiz@gazi.edu.tr 
Belirsizlik, eksik veriler ve karar vericinin algisıyla şekillenen bu karar süreci bulanık çok kriterli karar modellerinin kullanılmasıyla çözülmeye çalışılır.

Literatürde proje seçiminde bu gibi sorunlara çözüm olabilecek Analitik Hiyerarşik Process (AHP) (Saaty, 1980), Analitik A ̆g Süreci (ANP) (Saaty, 1996), Basit Toplamsal Ağırlık (SAW-Simple Additive Weigthing) (Fishburn, 1967), TOPSIS (Technique for Order Pre- ference by Similarity to Ideal Solution) (Hwang and Yoon, 1981) ve VIKOR (Sırpça: VlseKriijumsko Optimizacijo I Kompromisno Resenje) (Opricovic, 1998) yöntemleri gibi bulanıklaştırılmış çok kriterli karar verme yöntemlerinin kullanıldığg görülmektedir.

$\mathrm{Bu}$ çalışmaların çoğu AR-GE ve portföy projelerine yönelik olarak yapılmıştır. Tablo 1'de bu konuda yapılan çalışmalardan bir kısmı gösterilmektedir.

Tablo 1. Proje Seçimi Konusunda Yapılan Çalışmalar

\begin{tabular}{|c|c|c|}
\hline Yazar(lar) & Proje Konusu & Yöntem \\
\hline Poh, Ang \& Bai (2001) & AR-GE & AHP ve Karşılaştırmalı Analiz \\
\hline Chou, Chou \& Tzeng (2006) & Bilişim & $\begin{array}{l}\text { 2-Aşamalı bulanık çok kriterli karar } \\
\text { verme }\end{array}$ \\
\hline $\begin{array}{l}\text { Carlsson, Fuller, Heikkila, \& } \\
\text { Majender (2006) }\end{array}$ & \begin{tabular}{ll|} 
AR-GE & proje \\
portföyü &
\end{tabular} & $\begin{array}{lll}\text { Bulanık karma } & \text { tamsayılı } \\
\text { programlama } & & \end{array}$ \\
\hline Wang \& Hwang, 2007 & \begin{tabular}{ll|} 
AR-GE & proje \\
portföyü &
\end{tabular} & $\begin{array}{l}\text { Bulanık bütünleşik tamsayılı } \\
\text { programlama }\end{array}$ \\
\hline $\begin{array}{l}\text { Salehi \& Tavakkoli-Moghaddam } \\
\text { (2008) }\end{array}$ & $\begin{array}{ll}\text { Endüstriyel } & \text { proje } \\
\text { seçimi }\end{array}$ & Bulanık TOPSIS \\
\hline Tolga (2008) & AR-GE & $\begin{array}{l}\text { Gerçek opsiyon değerlemeye dayalı } \\
\text { bulanık TOPSIS }\end{array}$ \\
\hline Rafiei \& Rabbani (2009) & Kuruluş Yeri & Bulanık Ağ Süreci \\
\hline Tolga ve Kahraman (2009) & AR-GE & Çok Ölçütlü Bulanık AHP \\
\hline $\begin{array}{l}\text { Armaneri, } \quad \text { Özdağoğlu } \quad \text { ve } \\
\text { Yalçınkaya (2010) }\end{array}$ & Proje riski & Bulanık Simülasyon \\
\hline $\begin{array}{lll}\text { Ravanshadnia, } & \text { Rajaie, } & \& \\
\text { Abbasian }(2010) & & \end{array}$ & İnşaat & Karma Bulanık ÇKKV \\
\hline Saraçoğlu ve Odabaşı (2011) & $\begin{array}{l}\text { Gemi İnşa ve Sanal } \\
\text { Liman }\end{array}$ & $\begin{array}{l}\text { Bulanık mantık temelli çok amaçlı } \\
\text { karar verme optimizasyon } \\
\text { teknikleri }\end{array}$ \\
\hline Pinter \& Psunder (2011) & İnşaat projesi & M-TOPSIS \\
\hline $\begin{array}{l}\text { Fasanghari, Amalnick, } \\
\text { Chaharsooghi \& Ko (2011) }\end{array}$ & Bilişim & $\begin{array}{l}\text { Bulanık tamsayılı programlama, } \\
\text { bulanık Entropi }\end{array}$ \\
\hline $\begin{array}{l}\text { Fouladgar, Yazdani-Chamzini, } \\
\text { Yakhchali, Ghasempourabadi, \& } \\
\text { Badri (2011) }\end{array}$ & Proje Portföyü & Bulanık VIKOR \\
\hline $\begin{array}{l}\text { Mohaghar, Fathi } \\
\text { Turkayesh (2012) }\end{array}$ & AR-GE & Bulanık ANP, bulanık TOPSIS \\
\hline Ayan Yakıcı ve Perçin (2012) & AR-GE & Bulanık TOPSIS \\
\hline Rouendegh ve Erol (2012) & İnşaat & Bulanık ELEKTRE \\
\hline
\end{tabular}


$\mathrm{Bu}$ çalışmada ise bir teknoloji firması için en uygun proje seçimi için çok kriterli karar verme tekniklerinden (ÇKKV) olan VIKOR yöntemi bulanık teoriyle birleştirilerek kullanılmıştır. Çalışma diğer çalışmalardan ayrı olarak son yıllarda en çok kullanılan VIKOR tekniğini proje seçim sürecine uygulamıştır.

Bu kapsamda çalışma üç temel bölümü içermektedir. Çalıșmanın birinci bölümünün birinci kısmında bulanıklık kavramına ve kümesine ilişkin temel bilgiler verilmiş, ikinci kısmında VIKOR yöntemi anlatılmış ve üçüncü kısımda ise bulanık VIKOR yönteminin işleyişi açıklanmıştır. Çalışmanın ikinci bölümünü oluşturan uygulama bölümünde ise öncelikle proje seçimine ilişkin kriterler belirlenmiş ve bu kriterlere karar vericilerin verdikleri ağırlıklar tespit edilmiş, sonraki aşamada bu kriterlere göre projelere puan verilmiştir. Daha sonra belirlenen kriterlere ve alınan puanlara göre VIKOR yöntemi kullanılarak projelerin sıralaması yapılmıştır. Üçüncü ve son bölümde ise çalışmaya ilişkin genel değerlendirme yapılmıştır.

\section{Yöntem}

Çalışmada bulanık ÇKKV tekniklerinden bulanık VIKOR yöntemi kullanılmıştır. Bulanık ÇKKV tekniklerinde kriterler/özellikler ve göreli ağırlıklar genellikle bulanık sayılarla ifade edilir. Buradaki yaklaşım, kararların kesin ifadelerden ziyade niteliksel olarak ifade edilebilmesidir. Bu yöntemlerin mantığ dilsel olarak ifade edilen değerlendirmelerin bulanıklaştırılarak analizde kullanılmalarıdır. Çalışmanın bu kısmında bulanık mantık teorisi tanıtılmıs, daha sonraki bölümde bulanık VIKOR yönteminin işleyişi açıklanmıştır.

\section{Bulanık Mantık}

Bulanık mantık, Zadeh (1965) tarafından geliştirilen kişisel düşüncelerin sözel ifadelerle değerlendirilmesine yönelik olarak geliştirilen, bulanık kümelere, bulanık sayılara ve dilsel değişkenlere dayalı matematiksel tabanlı bir teoridir. Bu kapsamda, bulanık küme, kesin sınırları olmayan, kademeli geçişleri öngören ve belirli üyelik derecelerine sahip olan elemanların oluşturduğu bir küme olarak tanımlanır. Bulanık sayı ise verilen bir küme aralığında her biri 0 ile 1 arasında üyelik derecesine sahip konveks kümedir $(\mathrm{Hu}, \mathrm{Wu}$ and Cai, 2009). Bu kümenin elemanlarının tanımlan- masında üye veya üye değildir gibi kesin ifadelerden ziyade sayının üyeliği, üyelik derecesini belirleyen fonksiyonlarla tanımlanır (Zadeh, 1975). Bu üyelik fonksiyonlarının tanımlanmasında sayıların komşuluğu (yakınlığı) yaklaşımından yararlanılır ve üyelik fonksiyonları genellikle bu komşuluğun durumuna göre üçgensel üyelik fonksiyonları, yamuk üyelik fonksiyonları vb fonksiyonlarla gösterilir. Uygulamalarda çoğunlukla hesaplama kolaylı̆̆ı açısından

üçgensel üyelik fonksiyonları tercih edilir. $\mu_{A}(x)$ üçgensel üyelik fonksiyonu denklem l'de tanımlanmiştır (Triantaphyllou, 2000).

$\mu_{A}(x)= \begin{cases}0, & x<n_{1} \\ \frac{x-n_{1}}{n_{2}-n_{1}}, & n_{1} \leq x \leq n_{2} \\ \frac{n_{3}-x}{n_{3}-n_{2}}, & n_{2} \leq x \leq n_{3} \\ 0, & x>n_{3}\end{cases}$

Geliştirilen bu formüle göre bulanık küme $A=\left(n_{1}, n_{2}, n_{3}\right)$ olmalıdır. $\mathrm{n}_{1}, \mathrm{n}_{2}$ ve $\mathrm{n}_{3}$ üçgensel üyelik fonksiyonunda dilsel değişkenlerin değerlerini göstermektedir. $\mathrm{n}_{1}$ alt bulanık sayı değerini; $\mathrm{n}_{2}$ orta bulanık sayı değerini ve $n_{3}$ üst bulanık sayı değerini ifade etmektedir.

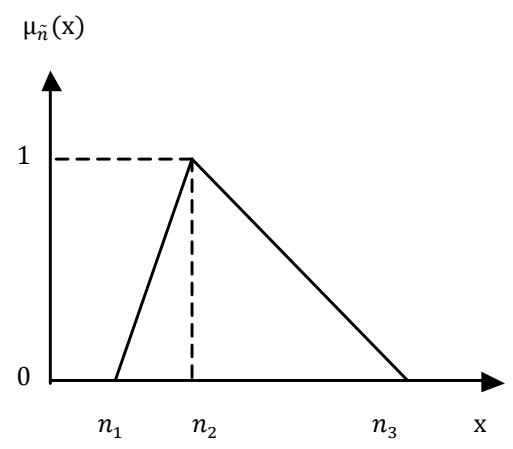

Şekil 1. Dilsel Değişkenler (Chen, 2000)

Dilsel değişkenler bu bulanık mantık kümesinin elemanlarının özelliklerini belirleyen değişkenlerdir. Örneğin bir nesnenin sıcaklığı belirtilmek istendiğinde sadece sicak, soğuk gibi kesin ifadelerden ziyade sıcak ve soğuk arasında olabilecek çok çok sıcak, orta sıcak, çok çok soğuk, çok soğuk gibi ara değerler de 
kullanılabilmek istenebilir. $\mathrm{Bu}$ gibi dilsel ifadelerin sayı değeri ise bulanık küme ve bulanık sayı tanımlamalarıyla belirlenebilir (Zadeh, 1975). Bulanık karar yöntemlerinde ise karar vericiler karar kriterlerinin önem düzeyini ve alternatiflerin değerlendirilmesini dilsel değiş̧kenleri kullanarak gerçekleştirirler.

\section{VIKOR Değerlendirme Yöntemi}

VIKOR yöntemi Opricovic tarafından geliştirilen (1998) özellikle sistem tasarımının başında karar vericinin tercihlerini belirleyememesi veya bilmemesi durumunda karar vermeye yardımci olmak üzere geliştirilmiş niteliksel çoklu karar verme yöntemidir (Opricovic ve Tzeng, 2007). Yöntemin amac1, uzlaşmacı bir çözüm ile maksimum grup faydası (çoğunluk kuralı) ve minimum bireysel pişmanlı̆̆ sağlayacak optimal bir uzlaşı çözüm bulmaktır. Uzlaşık sıralama için çok kriterli çözüm, uzlaşı programlamada toplama fonksiyonu olarak kullanılan Lp kriterinden geliştirilmiştir. Çeşitli i tane alternatif $\mathrm{C}_{1}$, $\mathrm{C}_{2}, \ldots . \mathrm{C}_{\mathrm{i}}$ olarak gösterilsin. $\mathrm{C}_{\mathrm{i}}$ seçeneğinin j’inci kriterinin ölçümü $\mathrm{f}_{\mathrm{ij}}$ olsun (Lai ve Hwang, 1996).

$L p_{i}=\left(\sum_{j=1}^{k}\left[w_{j}\left(f j i^{*}-f_{i j}\right) /\left(f j^{*}-f j^{-}\right)\right]^{p}\right)^{\frac{1}{p}}$

$J=1,2,3, \ldots \ldots, j \quad 1 \leq p \leq \infty$

Denklemde $\mathrm{L}_{\mathrm{pj}}$ ölçümü, tüm alternatifler ile pozitif ideal çözüm arasındaki uzaklığın normalize edilmiş değerlerini vermektedir. VIKOR yönteminde $L_{1 i}, S_{i}$ için ve $\mathrm{L}_{\infty \mathrm{i}}$ ise $\mathrm{R}_{\mathrm{j}}$ sıralama kriterinin formülasyonunda kullanılır. Maksimum grup faydası min $\mathrm{S}_{\mathrm{i}}$ den, minimum kişisel pişmanlık ise min $R_{i}$ den elde edilen çözümdür. j kriterinin ağırlığını belirtirken, en iyi değere sahip olan kriteri ve ise en kötü değere sahip olan kriteri göstermektedir.

Şekilsel olarak uzlaşık çözüm $\mathrm{F}^{c}$ ise, ideal değerine en yakın uygun çözümdür (Şekil 2). Uzlaşık çözüm şekilde görüldüğü üzere ve karşılıklı anlaşmalarına bağlı ortaya konan çözümü gösterir (Opricovic ve Tzeng, 2004).

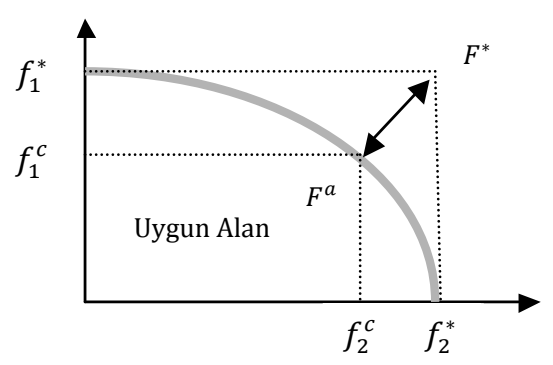

Şekil 2. İdeal ve Uzlaşık Çözümler (Opricovic ve Tzeng, 2004)

\section{Bulanık VIKOR Yöntemi}

Klasik çok kriterli karar verme tekniklerinde kriter ağırlıklarının ve değerlendirmelerin kesin olarak bilindiği varsayılır. Ancak gerçek hayatta bazı durumlarda kesin ifadeler kullanmak mümkün olmamaktadır. Bu soruna çözüm olarak Fayed (1965) tarafından geliştirilen bulanık mantık teorisinden faydalanılabilir. Böylece kesin olarak ifade edilemeyen değişkenler dilsel değerlerle ifade edilebilir. Bu teori çok kriterli karar verme tekniklerinde kullanılmaya başlanarak bulanık ÇKKV teknikleri geliştirilmiştir. Bunlardan biri de bulanık VIKOR yöntemidir. Bulanık VIKOR yönteminin son yıllarda farklı alanlarda kullanılmaya başlandığı görülmektedir. Bu çalışmalardan bazıları şunlardır: personel seçimi (Ersoylu, 2011; El_Santawy, 2012), tedarikçi seçimi (Chen ve Wang, 2009; Zıngıl, 2009; Akyüz, 2012); su kaynakları planlaması (Opricovic, 2011).

Bulanık VIKOR, elde edilen bulanık karar matris değerlerini kullanarak aşağıdaki aşamaları içeren bir algoritmadan oluşmaktadır (Chen ve Wang, 2009).

Adım 1: Öncelikle problemin çözümü için $\mathrm{n}$ sayıda karar verici, $m$ tane alternatif ve $\mathrm{k}$ tane değerlendirme kriteri belirlenir.

Adım 2: Dilsel değişkenler ve bu değişkenlerin karşlıkları üçgensel bulanık sayılar tanımlanır. Dilsel değişkenler kriter ağırlıklarını belirlemek ve alternatifleri derecelendirmek için kullanılır.

Adım 3: $\mathrm{wj}^{\mathrm{n}} \mathrm{n}$ tane karar vericiden oluşan bir kümede n'inci karar vericinin değerlendirdiği karar kriterinin önem ağırlığını; , j kriterine göre i alternatifinin derecesini göstersin. Karar kriterlerinin önem ağırlıkları ve alternatiflerin kriter değerleri aşağıdaki eşitlikler yardımıyla her biri için tek bir değerlendirme olacak şekilde birleştirilir ve bütünleştirilmiş değerler elde edilir (Chen ve diğerleri, 2006). 


$$
\begin{aligned}
\widetilde{\mathrm{w}}_{\mathrm{j}} & =\frac{1}{\mathrm{n}}\left[\widetilde{\mathrm{w}}_{\mathrm{j}}{ }^{1}(+) \widetilde{\mathrm{w}}_{\mathrm{j}}{ }^{2}(+) \ldots(+) \widetilde{\mathrm{w}}_{\mathrm{j}}{ }^{\mathrm{n}}\right] \\
\widetilde{\mathrm{x}}_{\mathrm{ij}} & =\frac{1}{\mathrm{n}}\left[\widetilde{\mathrm{x}}_{\mathrm{ij}}{ }^{1}(+) \widetilde{\mathrm{x}}_{\mathrm{ij}}{ }^{2}(+) \ldots(+) \widetilde{\mathrm{x}}_{\mathrm{ij}}{ }^{\mathrm{n}}\right]
\end{aligned}
$$

Denklemlerde $\tilde{x}_{i j} \quad$ ve $\widetilde{w}_{j}$ değerleri, sözel değişkenlerin karşılığı olan üçgensel bulanık sayı değerlerini göstermektedir.

Adım 4: Tüm kriter ve alternatifler için tek bir değer elde edildikten sonra, $\mathrm{j}$ kriterli ve i alternatifli bir bulanık karar matrisi ve ağırlık matrisi oluşturulur.

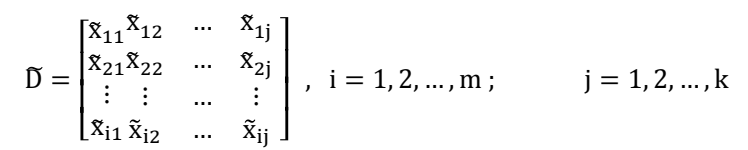

$\widetilde{\mathrm{W}}=\left[\widetilde{\mathrm{w}}_{1}, \widetilde{\mathrm{w}}_{2}, \ldots \ldots . \widetilde{\mathrm{w}}_{\mathrm{j}}\right]$,

$\mathrm{x}_{\mathrm{ij}}$, j. kritere göre $\mathrm{i}$. alternatifin derecesi ve ise j.kriterin önem ağırlığıdır.

Adım 5: Bulanık karar matrisinde tüm kriter fonksiyonlarının en iyi $\tilde{\mathrm{f}}_{\mathrm{j}}^{*}$ ve en kötü $\tilde{\mathrm{f}}_{\mathrm{j}}^{-}$değerleri 6. ve 7 . formüller yardımılla belirlenir.

$$
\begin{aligned}
& \mathrm{f}_{\mathrm{j}}^{*}=\max _{\mathrm{j}} \mathrm{x}_{\mathrm{ij},}, \quad \mathrm{j} \in \mathrm{J} \text { fayda ölçüleri; } \quad \tilde{\mathrm{f}}_{\mathrm{j}}^{*}=\min \mathrm{x}_{\mathrm{ij},}, \quad \mathrm{j} \in \mathrm{J} \text { maliyet ölçüleri } \\
& \mathrm{f}_{\mathrm{j}}^{-}=\min _{\mathrm{j}} \mathrm{x}_{\mathrm{ij}}, \quad \mathrm{j} \in \mathrm{J} \text { fayda ölçüleri; } \quad \tilde{\mathrm{f}}_{\mathrm{j}}^{-}=\max _{\mathrm{j}} \mathrm{x}_{\mathrm{ij}}, \quad \mathrm{j} \in \mathrm{J} \text { maliyet ölçüleri }
\end{aligned}
$$

Adım 6: $\widetilde{\mathrm{w}}_{\mathrm{j}}$ kriterlerin ağırlığını ve önemini ifade etsin. Denklem 8 yardımıyla ilgili bütün kriterlere göre i. alternatifin en iyi bulanık değere uzaklığının toplamını veren $\widetilde{S}_{i}$ değeri elde edilir.

$$
\mathrm{S}_{\mathrm{i}}=\sum_{\mathrm{j}=1}^{\mathrm{n}}\left[\widetilde{\mathrm{w}}_{\mathrm{j}}\left(\tilde{\mathrm{f}}_{\mathrm{j}}^{*}-\tilde{\mathrm{f}}_{\mathrm{ij}}\right) /\left(\tilde{\mathrm{f}}_{\mathrm{j}}^{*}-\tilde{\mathrm{f}}_{\mathrm{ji}}^{-}\right)\right]
$$

Denklem 9'da gösterilen $\widetilde{R}_{\mathrm{i}}$ değerleri ise j. kritere göre i. alternatifin bulanık en kötü değerlere olan maksimum uzaklığıdır. $\tilde{\mathrm{f}}_{\mathrm{ij}}$, j kriteri açısından $\mathrm{A}_{\mathrm{i}}$ alternatifi için performans skorunu gösterir.

$$
\mathrm{R}_{\mathrm{i}}=\max \left[\widetilde{w}_{\mathrm{j}}\left(\mathrm{f}_{\mathrm{j}}^{*}-\mathrm{f}_{\mathrm{ij}}\right) /\left(\mathrm{f}_{\mathrm{j}}^{*}-\mathrm{f}_{\mathrm{j}}^{-}\right)\right] \text {, }
$$

$\underline{\operatorname{Ad} \imath m} 7: \mathrm{S}^{*}$ maksimum çoğunluk kuralını ve $\widetilde{\mathrm{R}}^{*}$ ise farklı görüştekilerin minimum bireysel pişmanlığını ifade etmek üzere $S^{-}{ }_{i}, S^{*}{ }_{i}(10)$ ve $\widetilde{R}^{-}{ }_{i}, \widetilde{R}^{*}{ }_{i}$ değerleri hesaplanir.

$$
\begin{aligned}
& \mathrm{S}^{*}=\min _{\mathrm{i}} \mathrm{S}_{\mathrm{i}} \quad \mathrm{S}^{-}{ }_{\mathrm{i}}=\max _{\mathrm{i}} \\
& \mathrm{R}^{*}{ }_{\mathrm{i}}=\min _{\mathrm{i}} \mathrm{R}_{\mathrm{i}}, \quad, \quad \mathrm{R}^{-}{ }_{\mathrm{i}}=\max \mathrm{R}_{\mathrm{i}}
\end{aligned}
$$

$\mathrm{S}^{*}$ ve $\widetilde{\mathrm{R}}^{*}$ değerlerinin minimum değerleri alınır, çünkü bireysel pişmanlık daha azdır ve istenilen/arzu edilen değere daha yakındır.

Adım 8: Bu hesaplamalardan sonra $\widetilde{\mathrm{Q}}_{\mathrm{i}}$ indeksi (12) elde edilir. $\widetilde{\mathrm{Q}}_{\mathrm{i}}$ indeksi, grup faydası ile bireysel pişmanlığ ${ }_{1}$ birlikte değerlendirilmesi ile hesaplanır.
$\widetilde{\mathrm{Q}}_{\mathrm{i}}=\mathrm{v}\left(\widetilde{\mathrm{S}}_{\mathrm{i}}-\mathrm{S}^{*}\right) /\left(\mathrm{S}^{-}-\widetilde{S}^{*}\right)+(1-\mathrm{v})\left(\widetilde{\mathrm{R}}_{\mathrm{i}}-\widetilde{\mathrm{R}}^{*}\right) /\left(\widetilde{\mathrm{R}}^{-}-\widetilde{\mathrm{R}}^{*}\right)$

Denklemdeki v değeri maksimum grup faydasını sağlayan stratejinin önemini ifade eder iken, 1-v bireysel pişmanlık değerini ifade eder. Uzlaşmacı çoğunluk için genellikle $\mathrm{v} \approx 0.5$ alınır (Opricovic, 2011).

Adım 9: Bu aşamada üçgensel bulanık sayılar durulaştırılır. Bu çalışmada Hsieh vd. (2004) tarafından önerilen ve 13. eşitlikte verilen En İyi Gerçek Sayı Değeri (Best Nonfuzzy Performance Value - BNP ) durulaştırma yöntemi kullanılmıştır.

$\mathrm{BNP}_{\mathrm{i}}=\frac{\left(\mathrm{n}_{3}-\mathrm{n}_{1}\right)+\left(\mathrm{n}_{2}-\mathrm{n}_{1}\right)}{3}+\mathrm{n}_{1}$

$\mathrm{n}_{3}$, üçgen bulanık sayının üst değerini; $\mathrm{n}_{2}$, orta değerini ve $\mathrm{n}_{1}$, ise alt değerini göstermektedir.

Daha sonra elde edilen $\mathrm{Q}_{\mathrm{i}}$ indeks değerine göre alternatifler sıralanır. Bu indeksin en küçük değeri en iyi alternatifi gösterir.

Adım 10: $\mathrm{Bu}$ aşamada belirlenen en iyi alternatifin uzlaştırıcı çözüm olup olmadığının belirlenmesi gerekir. Uzlaştırıcı çözümü belirlemek için aşağıdaki iki koşulun sağlanıp sağlanmadığı kontrol edilmelidir.

1.Koşul: Kabul edilebilir avantaj: Bu koşul en iyi ve en yakın seçenek arasında belirgin bir fark olduğunun kanıtlanmasını içeren koşuldur. 
$Q\left(A^{\prime \prime}\right)-Q\left(A^{\prime}\right) \geq D Q \quad D Q=\frac{1}{m-1} ;$

$m$ alternatif sayısını ifade eder.

$(\mathrm{m} \leq 4$ ise $\mathrm{DQ}=0.25)$

$\mathrm{A}^{\prime}$ değeri sıralamada birinci sırada yer alan alternatif ve A" siralamada en iyi ikinci alternatifi gösterir.

\section{Koşul: Kabul edilebilir istikrar}

Alternatif $\mathrm{a}^{\prime}$, $\mathrm{S}$ ve/veya $\mathrm{R}$ değerlerine göre yapılan sıralamada en iyi alternatif olmalıdır (Opricovic ve Tzeng, 2004).

Eğer 1. koşul sağlanmaz ise $Q\left(A^{m}\right)-Q\left(A^{\prime}\right) \leq$ DQ olursa, $a^{(m)}$ ve a' aynı uzlaştırıcı çözüm olur. Eğer 2. koşul kabul edilmezse, her ne kadar A' 'nın nispi bir avantajı olsa da karar vermede tutarsızlık vardır. Bundan dolayı A've A" uzlaștırıcı çözümleri aynıdır. Q değeri minimum olan en iyi alternatifin seçimi yapılır.

\section{Uygulama}

Proje seçim kriterleri çoğu zaman belirsiz bir ortamda birbirleriyle çelişen, çok sayıda kriteri içeren bir karardır. Bu kararı verirken farklı kriterlerin ve bu kriterleri sağlayan alternatiflerin değerlendirilmesi gerekir. Şekil 3'de proje seçim sürecine ilişkin hiyerarşik yapı ortaya konmuştur. Şekil 3'de görüldüğü üzere 5 tane alternatif $\left(A_{1}, A_{2}, \ldots . . A_{5}\right)$ ve yedi tane kriter $\left(K_{1}, K_{2}, \ldots \ldots \ldots \ldots K_{7}\right)$ üzerinden değerlendirme yapılmıştır.

Hiyerarşik yapının belirlenmesinden sonra en uygun proje seçimi için bulanık VIKOR yönteminin algoritmasındaki aşamalar gerçekleştirilmiştir.

Adım 1: Öncelikle karar verici grup oluşturulur. Çalışmada alanında uzman 5 karar vericinin görüşlerine başvurulmuştur. Daha sonra bu karar vericilerin görüşleri doğrultusunda tablo 2'de gösterilen değerlendirme kriterleri belirlenmiştir.

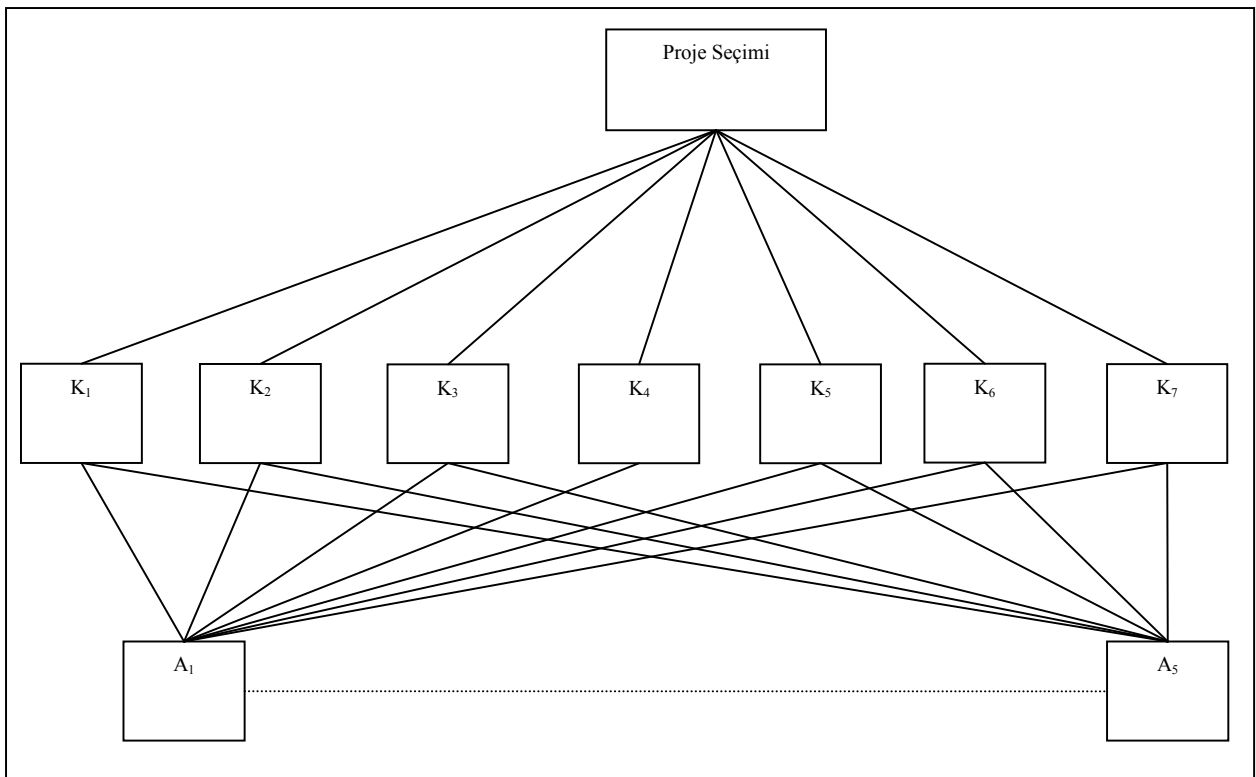

Şekil 3. Proje Seçim Sürecinin Hiyerarşik Yapısı 
Tablo 2. Karar Kriterleri

\begin{tabular}{|c|l|}
\hline \hline Kriterler & Açılama \\
\hline \hline$\left(\mathrm{K}_{1}\right)$ & Projenin Net Bugünkü Değeri \\
\hline$\left(\mathrm{K}_{2}\right)$ & Geri Dönüşüm Oranı \% \\
\hline$\left(K_{3}\right)$ & Geri Dönüşüm Süresi: Yll \\
\hline$\left(K_{4}\right)$ & Risk \\
\hline$\left(\mathrm{K}_{5}\right)$ & Büyüme Beklentisi \\
\hline$\left(\mathrm{K}_{6}\right)$ & Uygulanabilirliği \\
\hline$\left(\mathrm{K}_{7}\right)$ & Firma Başarısına Katkısı \\
\hline
\end{tabular}

$\mathrm{Bu}$ kriterlerden projenin geri dönüşüm süresi ile risk kriterleri minimize edilmeye çalışılırken, diğer kriterler maksimize edilmeye çalışılır (Fouladgar ve diğerleri, 2011). Karar vericiler bu kriterlere dayalı olarak ellerindeki beş alternatif projeyi değerlendirmişlerdir.

Adım 2: Bu aşamada, kriterleri ve alternatifleri değerlendirmek için uygun dilsel (sözel) değişkenler seçilmelidir. Kriterlerin ağırlı̆̆ının ve alternatiflerin önem derecelerini belirlemek için kullanılan sözel değişkenler ve bulanık sayılar (Chen, 2000) Tablo 3'de verilmiştir. Şekil 4'de ise dilsel değişkenler bulanık üyelik fonksiyonları ile birlikte gösterilmiştir. Şekilden görüldüğü üzere her bir dilsel değişken birden fazla kümeye ait olabilmekte ve üyelik fonksiyonu 0 ile 1 arasında değer almaktadır.

Adım 3: Daha sonra karar vericilerin değerlendirmeleri doğrultusunda elde edilen kriter değerlendirmeleri 3. eşitlik yardımıyla bulanık ağırlık matrisine dönüştürülür.

\section{Tablo 3. Kriter ve Alternatifleri Değerlendirmek İçin Dilsel Değişkenler}

\begin{tabular}{|c|c|c|c|}
\hline $\begin{array}{l}\text { Kriter Ağırlıkları iç } \\
\text { Değişkenler }\end{array}$ & & $\begin{array}{l}\text { Alternatiflerin De } \\
\text { Değişkenler }\end{array}$ & irilmesi için Dilsel \\
\hline Dilsel Değişkenler & Bulanık Sayılar & Dilsel Değişkenler & Bulanık Sayılar \\
\hline Çok Düşük (ÇD) & $(0,0,0.1)$ & Çok Kötü (ÇK) & $(0,0,1)$ \\
\hline Düşük (D) & $(0,0.1,0.3)$ & Kötü (K) & $(0,1,3)$ \\
\hline Orta Düşük (OD) & $(0.1,0.3,0.5)$ & Orta Kötü (OK) & $(1,3,5)$ \\
\hline Orta $(\mathrm{O})$ & $(0.3,0.5,0.7)$ & Orta $(\mathrm{O})$ & $(3,5,7)$ \\
\hline Orta Yüksek (OY) & $(0.5,0.7,0.9)$ & Orta İyi (OI) & $(5,7,9)$ \\
\hline Yüksek (Y) & $(0.7,0.9,1)$ & İyi(I) & $(7,9,10)$ \\
\hline Çok Yüksek (ÇY) & $(0.9,1,1)$ & Çok İyi (Çİ) & $(9,10,10)$ \\
\hline
\end{tabular}




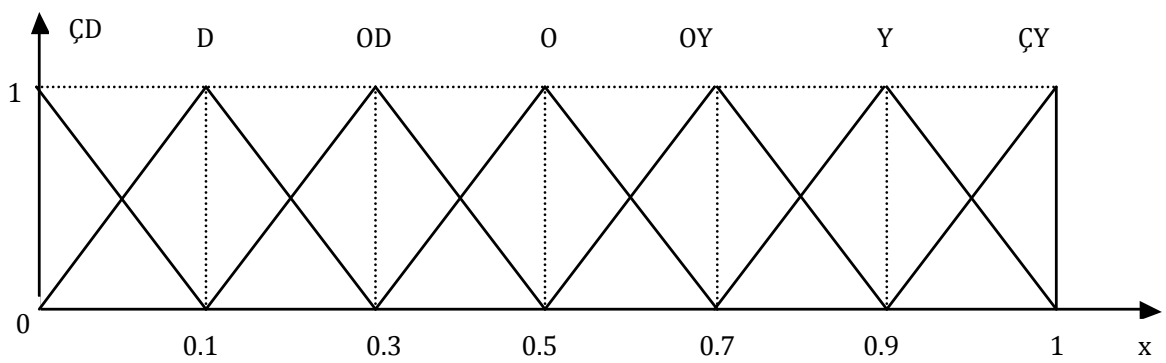

Şekil 4. Dilsel Değerlerin Bulanık Üyelik Fonksiyonları ile Gösterimi (Büyüközkan ve Çiftçi, 2012)

Tablo 5. Kriterlerin Bulanık Ağırlık Matrisi

\begin{tabular}{|c|c|c|c|}
\hline \multirow{2}{*}{ Kriterler } & \multicolumn{3}{|c|}{ Bulanık Ağırlıklar } \\
\cline { 2 - 4 } & $\mathrm{n}_{1}$ & $\mathrm{n}_{2}$ & $\mathrm{n}_{3}$ \\
\hline $\mathrm{K}_{1}$ & 0,50 & 0,67 & 0,80 \\
\hline $\mathrm{K}_{2}$ & 0,50 & 0,70 & 0,87 \\
\hline $\mathrm{K}_{3}$ & 0,50 & 0,67 & 0,80 \\
\hline $\mathrm{K}_{4}$ & 0,43 & 0,60 & 0,73 \\
\hline $\mathrm{K}_{5}$ & 0,63 & 0,83 & 0,97 \\
\hline $\mathrm{K}_{6}$ & 0,30 & 0,50 & 0,70 \\
\hline $\mathrm{K}_{7}$ & 0,77 & 0,90 & 0,97 \\
\hline
\end{tabular}

Tablo 5'den büyüme beklentisi ve firmaya katkısı kriterlerinin daha fazla önem derecesine (ağırlı̆̆ına) sahip olduğu görülmektedir. Bu sonuç klasik yaklaşımlarda önemli olan maliyet, geri ödeme süresi gibi finansal kriterlere fazla önem verilmediğini, sürecin daha çok stratejik boyutta ve eldeki diğer projelerle birlikte ele alındığını göstermektedir. Karar vericiler tarafindan ortaya konan bu yaklaşım uzun dönemde izlenmesi gereken doğru bir yaklaşımdır.

Adım 4: Belirlenen kriterler çerçevesinde her bir alternatifin karar vericiler tarafından değerlendirilmesi eşitlik 4 yardımıyla birleştirilir. Elde edilen değerler ile tablo 6'da gösterilen bulanık karar matrisi oluşturulur.

Tablo 6. Bulanık Karar Matrisi

\begin{tabular}{|c|c|c|c|c|c|c|c|c|c|c|c|c|c|c|c|}
\hline & \multicolumn{3}{|c}{$\mathrm{A}_{1}$} & \multicolumn{5}{c|}{$\mathrm{A}_{2}$} & \multicolumn{3}{c|}{$\mathrm{A}_{3}$} & \multicolumn{3}{c|}{$\mathrm{A}_{4}$} & \multicolumn{3}{c|}{$\mathrm{A}_{5}$} \\
\cline { 2 - 15 } & $\mathrm{n}_{1}$ & $\mathrm{n}_{2}$ & $\mathrm{n}_{3}$ & $\mathrm{n}_{1}$ & $\mathrm{n}_{2}$ & $\mathrm{n}_{3}$ & $\mathrm{n}_{1}$ & $\mathrm{n}_{2}$ & $\mathrm{n}_{3}$ & $\mathrm{n}_{1}$ & $\mathrm{n}_{2}$ & $\mathrm{n}_{3}$ & $\mathrm{n}_{1}$ & $\mathrm{n}_{2}$ & $\mathrm{n}_{3}$ \\
\hline $\mathrm{K}_{1}$ & 5,67 & 7,67 & 9,33 & 5,00 & 7,00 & 8,67 & 8,33 & 9,67 & 10,00 & 1,67 & 3,67 & 5,67 & 1,67 & 3,67 & 5,67 \\
\hline $\mathrm{K}_{2}$ & 6,33 & 8,00 & 9,33 & 3,67 & 5,67 & 7,67 & 8,33 & 9,67 & 10,00 & 1,67 & 3,67 & 5,67 & 8,33 & 9,67 & 10,00 \\
\hline $\mathrm{K}_{3}$ & 3,00 & 5,00 & 7,00 & 3,00 & 4,00 & 5,33 & 2,33 & 4,33 & 7,67 & 7,67 & 9,33 & 10,00 & 3,67 & 5,67 & 7,67 \\
\hline $\mathrm{K}_{4}$ & 9,00 & 10,00 & 10,00 & 6,33 & 8,33 & 9,67 & 7,33 & 8,67 & 6,33 & 2,33 & 4,33 & 6,33 & 8,33 & 9,67 & 10,00 \\
\hline $\mathrm{K}_{5}$ & 3,67 & 5,67 & 7,67 & 1,67 & 3,67 & 5,67 & 8,33 & 9,67 & 10,00 & 3,00 & 5,00 & 7,00 & 1,67 & 3,67 & 5,67 \\
\hline $\mathrm{K}_{6}$ & 0,00 & 1,00 & 3,00 & 3,67 & 5,67 & 7,67 & 3,67 & 5,67 & 7,67 & 1,67 & 3,67 & 5,67 & 5,67 & 7,67 & 9,33 \\
\hline $\mathrm{K}_{7}$ & 2,33 & 4,33 & 6,33 & 8,33 & 9,67 & 10,00 & 7,67 & 9,33 & 10,00 & 7,00 & 9,00 & 10,00 & 3,67 & 5,67 & 7,67 \\
\hline
\end{tabular}


Adım 5: Bulanık karar matrisinde yer alan en iyi $\left.\widetilde{(f}_{\mathrm{j}}^{*}\right)$ ve en kötü $\left(\tilde{f}_{j}\right)$ kriter değerleri belirlenir. Burada dikkat edilmesi gereken nokta geri ödeme süresi ve risk kriterleri için minimum değerler en iyi bulanık değerleri verirken, maksimum değerler en kötü kriter değerlerini oluşturacaktır. Elde edilen sonuçlar tablo 7 'de gösterilmiştir.

$\underline{\operatorname{Ad} \imath m}$ 6: 8. ve 9. eşitliklerinden faydalanarak alternatiflerin $S_{i}$ ve $R_{i}$ değerleri hesaplanır.

Tablo 7. Bulanık En İi ${\widetilde{\left(\mathrm{f}_{\mathrm{j}}^{*}\right.}}_{\mathrm{j}}^{*}$ ve Bulanık En Kötü $\tilde{\mathrm{f}}_{\mathrm{j}}^{-}$Kriter Değerleri

\begin{tabular}{|c|c|c|c|c|c|c|}
\hline \multirow{2}{*}{ Kriterler } & \multicolumn{3}{|c|}{$\left.\mathrm{F}^{*}\right)$} & \multicolumn{3}{c|}{$\mathrm{F}(-)$} \\
\cline { 2 - 7 } & $\mathrm{n}_{1}$ & $\mathrm{n}_{2}$ & $\mathrm{n}_{3}$ & $\mathrm{n}_{1}$ & $\mathrm{n}_{2}$ & $\mathrm{n}_{3}$ \\
\hline $\mathrm{K}_{1}$ & 8,33 & 9,67 & 10,00 & 1,67 & 3,67 & 5,67 \\
\hline $\mathrm{K}_{2}$ & 8,33 & 9,67 & 10,00 & 1,67 & 3,67 & 5,67 \\
\hline $\mathrm{K}_{3}$ & 3,00 & 4,00 & 5,33 & 7,67 & 9,33 & 10,00 \\
\hline $\mathrm{K}_{4}$ & 2,33 & 4,33 & 6,33 & 9,00 & 10,00 & 10,00 \\
\hline $\mathrm{K}_{5}$ & 8,33 & 9,67 & 10,00 & 1,67 & 3,67 & 5,67 \\
\hline $\mathrm{K}_{6}$ & 5,67 & 7,67 & 9,33 & 0,00 & 1,00 & 3,00 \\
\hline $\mathrm{K}_{7}$ & 8,33 & 9,67 & 10,00 & 2,33 & 4,33 & 6,33 \\
\hline
\end{tabular}

Tablo 8. $S_{i}$ ve $R_{i}$ Değerleri

\begin{tabular}{|c|c|c|c|c|c|c|}
\hline \multirow{2}{*}{ Alternatifler } & \multicolumn{3}{|c|}{$\mathrm{Si}$} & \multicolumn{3}{c|}{$\mathrm{Ri}$} \\
\cline { 2 - 7 } & $\mathrm{n}_{1}$ & $\mathrm{n}_{2}$ & $\mathrm{n}_{3}$ & $\mathrm{n}_{1}$ & $\mathrm{n}_{2}$ & $\mathrm{n}_{3}$ \\
\hline $\mathrm{A}_{1}$ & 2,293 & 3,097 & 3,463 & 0,767 & 0,900 & 0,967 \\
\hline $\mathrm{A}_{2}$ & 1,599 & 2,170 & 2,530 & 0,633 & 0,833 & 0,967 \\
\hline $\mathrm{A}_{3}$ & 0,445 & 0,707 & 0,584 & 0,571 & 0,625 & 0,400 \\
\hline $\mathrm{A}_{4}$ & 2,388 & 3,094 & 3,541 & 0,500 & 0,700 & 0,867 \\
\hline $\mathrm{A}_{5}$ & 2,191 & 2,948 & 3,515 & 0,633 & 0,833 & 0,967 \\
\hline
\end{tabular}


Adım 7: Sırasıyla 10 ve 11 numaralı eşitlikler kullanılarak $S^{*}, S^{-}$ve $R^{*}$ ve $\widetilde{R}^{-}$değerleri bulunur. $S^{*}$ ve $R^{*}$ değerleri ideal çözümden minimum uzaklik değerlerini verirken, $S^{-}$ve $R^{-}$ise maksimum uzaklık değerlerini vermektedir.

Tablo 9. $\boldsymbol{S}^{*}, \boldsymbol{S}^{-}, \boldsymbol{R}^{*}$ ve $\boldsymbol{R}^{-}$Değerleri
\begin{tabular}{|c|c|c|c|}
\hline & $\mathrm{n}_{1}$ & $\mathrm{n}_{2}$ & $\mathrm{n}_{3}$ \\
\hline$S^{*}$ & 0,445 & 0,707 & 0,584 \\
& & & \\
\hline$S^{-}$ & 2,388 & 3,097 & 3,541 \\
\hline$R^{*}$ & 0,500 & 0,625 & 0,400 \\
\hline$R^{-}$ & 0,767 & 0,900 & 0,967 \\
\hline
\end{tabular}

Adım 8: Tablo 9'da bulunan değerler 12 numaralı eşitlikte yerine konularak tablo 10 'da gösterilen $Q_{i}$ değerleri bulunur.

Tablo 10. $\widetilde{Q}_{i}$ Değerleri

\begin{tabular}{|c|c|c|c|}
\hline \multirow{2}{*}{ Alternatifler } & \multicolumn{3}{|c|}{$Q_{i}$} \\
\cline { 2 - 4 } & $\mathrm{n}_{1}$ & $\mathrm{n}_{2}$ & $\mathrm{n}_{3}$ \\
\hline $\mathrm{A}_{1}$ & 0,976 & 1,000 & 0,987 \\
\hline $\mathrm{A}_{2}$ & 0,547 & 0,685 & 0,829 \\
\hline $\mathrm{A}_{3}$ & 0,134 & 0,000 & 0,000 \\
\hline $\mathrm{A}_{4}$ & 0,500 & 0,636 & 0,912 \\
\hline $\mathrm{A}_{5}$ & 0,699 & 0,848 & 0,996 \\
\hline
\end{tabular}

Adım 9: 13. eşitlik ile bulanık üçgensel değerleri durulaştırılır ve tablo 11'de gösterilen değerler elde edilir.

Minimum $Q_{i}$ değerine sahip alternatif en iyi çözüm olarak belirlendiğinden $A_{3}$ alternatifi en iyi çözüm olarak bulunmuştur. $\mathrm{A}_{1}$ alternatifi ise en kötü performans gösteren alternatif olmuştur. Ayrıca $Q_{i}$ indeksi ile uzlaşık çözüm karar sürecinde kullanılmak üzere $S_{i}$ ve $R_{i}$ değerleri elde edilir. Tablo 12'de alternatiflerin $\mathrm{Q}_{i}, \mathrm{~S}_{\mathrm{i}}$ ve $\mathrm{R}_{\mathrm{i}}$ indeks değerleri birlikte gösterilmiştir.

\section{Tablo 11. Durulaştırılan (Gerçek Sayıya Dönüştürülen) $Q_{i}$ Değerleri}

\begin{tabular}{|c|c|}
\hline Alternatifler & $\mathrm{Q}_{\mathrm{i}}$ Değerleri \\
\hline $\mathrm{A}_{1}$ & 0,987 \\
\hline $\mathrm{A}_{2}$ & 0,687 \\
\hline $\mathrm{A}_{3}$ & 0,045 \\
\hline $\mathrm{A}_{4}$ & 0,683 \\
\hline $\mathrm{A}_{5}$ & 0,847 \\
\hline
\end{tabular}

Daha sonra elde edilen indeks değerlerine göre alternatiflerin sıralaması yapılmış ve tablo 13'de gösterilmiştir.

Adım 10: Bulunan $\mathrm{Q}_{\mathrm{i}}$ indeks değerine sahip $\mathrm{A}_{3}$ alternatifi en iyi çözümdür. Ancak en iyi uzlaştırıcı çözümü sağlayıp sağlamadığını belirlemek için aşağıdaki iki koşulun uygunluğu kontrol edilmelidir.

1. Koșul: Kabul edilebilir avantaj: 14. eşitliğe göre; $Q\left(A^{\prime \prime}\right)-Q\left(A^{\prime}\right) \geq 0.25$ koşulu sağlanmalıdır. Tablo 12 ye göre $0.683-0.045 \geq 0.25$ olduğundan $A_{3}$ alternatifi kabul edilebilir avantaj koşulunu sağlamaktadır.

Tablo 12. Alternatiflerin $Q_{f} S_{i}$ ve $R_{i}$ Indeks Değerleri

\begin{tabular}{|c|c|c|c|c|c|c|}
\hline & \multicolumn{2}{|c|}{$\mathrm{Q}_{\mathrm{i}}$} & \multicolumn{2}{c|}{$\mathrm{S}_{\mathrm{i}}$} & \multicolumn{2}{c|}{$\mathrm{R}_{\mathrm{i}}$} \\
\hline Alternatifler & İndeks & Sira & İndeks & S1ra & İndeks & S1ra \\
\hline $\mathrm{A}_{1}$ & 0,987 & 5 & 2,951 & 4 & 0,878 & 4 \\
\hline $\mathrm{A}_{2}$ & 0,687 & 3 & 2,100 & 2 & 0,811 & 3 \\
\hline $\mathrm{A}_{3}$ & 0,045 & 1 & 0,579 & 1 & 0,532 & 1 \\
\hline $\mathrm{A}_{4}$ & 0,683 & 2 & 3,008 & 5 & 0,689 & 2 \\
\hline $\mathrm{A}_{5}$ & 0,847 & 4 & 2,885 & 3 & 0,811 & 3 \\
\hline
\end{tabular}


Tablo 13. Alternatiflerin $Q_{f} S_{i} v e R_{i}$ Indeks Değerlerine Göre Siralamaları

\begin{tabular}{|l|l|}
\hline$Q_{i}$ & $\mathrm{~A}_{3}>\mathrm{A}_{4}>\mathrm{A}_{2}>\mathrm{A}_{5}>\mathrm{A}_{1}$ \\
\hline$S_{i}$ & $\mathrm{~A}_{3}>\mathrm{A}_{2}>\mathrm{A}_{5}>\mathrm{A}_{1}>\mathrm{A}_{4}$ \\
& $\mathrm{~A}_{3}>\mathrm{A}_{4}>\mathrm{A}_{2}=\mathrm{A}_{5}>\mathrm{A}_{1}$ \\
\hline$R_{i}$ & \\
\hline
\end{tabular}

2. Koşul: Kabul edilebilir istikrar: Bu koşula göre $\mathrm{A}^{\prime}$ alternatifi $\mathrm{S}$ ve/veya $\mathrm{R}$ indeks değerlerine göre s1ralamada en iyi alternatif olmalıdır. Tablo 13 incelendiğinde $\mathrm{A}_{3}$ alternatifinin hem $\mathrm{S}$ hem de $\mathrm{R}$ indeks değerlerine göre birinci sırada yer aldığı görülmektedir. Böylece alternatif $\mathrm{A}_{3}$ kabul edilebilir istikrar koşulunu sağlamaktadır.

$\mathrm{Bu}$ sonuçlara göre her iki koşulu da sağlayan $\mathrm{A}_{3}$ alternatifi en iyi uzlaşık çözümü veren alternatiftir. Diğer alternatif projelere ilişkin sıralamalar tablo 13'de gösterilmiştir.

\section{Genel Değerlendirme ve Sonuç}

Bu çalışmada bir teknoloji firması için birçok karar vericinin içinde yer aldığı, birbirleriyle çelişkili birçok nicel ve niteliksel faktörün dikkate alındığ 1 iş sürecini geliştirme projesinin seçim sürecinde bulanık VIKOR yöntemi kullanılarak sürecin daha objektif, daha etkin gerçekleştirilmesi amaçlanmıştır. Firma, proje değerlendirme kriterleri olarak projenin net bugünkü değeri, geri dönüşüm oranı, geri dönüşüm süresi, risk, büyüme beklentisi, uygulanabilirliği ve firma başarısına katkısını belirlemiştir. Bu kriterler içinde büyüme beklentisi ve firma başarısına katkısı kriterlerinin ağırlıklarının, diğer bir deyişle verilen önemin daha fazla olduğu görülmüştür. $\mathrm{Bu}$ sonuç klasik yaklaşımda maliyet, geri ödeme süresi gibi finansal kriterlerin önem ağırlıklarının azaldığını göstermektedir. Aslında son zamanlarda yapılan çalışmalar da sadece finansal göstergelerin esas alındığ 1 proje seçimlerinde birçok projenin amacına ulaşmadığını ve katlanılan maliyetlerin boşa gittiğini göstermektedir. Bu nedenle günümüzde izlenen yaklaşım stratejik hedeflerle uyumlu işletme amaçlarına hizmet eden projelere daha fazla öncelik verilmesi gerektiği yönündedir. Çalışmada kriter değerlendirmeleri incelendiğinde karar vericilerin bu bakış açısına sahip olduğu ortaya çıkmıştır. Alternatiflerin değerlendirilmesine ilişkin süreç ise bulanık VIKOR yöntemindeki aşamalar izlenerek tamamen karar vericilerin ortak görüşüyle belirlenen ve istenen özellikleri ve koşulları yerine getiren alternatif çözümün bulunmasıyla sonuçlanmıştır.

Önerilen yaklaşım kriterler, kriter ağırlıkları ve alternatifler değiştirilerek firma tarafından daha sonra farklı projeler için de kullanılabilir. Hatta bir adım ileriye gidilerek oluşturulan süreç bilgisayar programı olarak geliştirilerek grup karar verme sürecine dönüştürülebilir.

$\mathrm{Bu}$ çalışmanın uzantısı olarak ileride finansal göstergelerin sayısal değerlerle, karar vericilerinin nitel değerlendirmelerinin bulanık değerlerle ifade edildiği yeni bir karma model geliştirilebilir. Böylece her bir değişken kendi gerçek ölçüm değerleriyle değerlendirilmiş olacaktır. Ayrıca karar kriter sayısı, kriter ağırlıkları, karar verici sayısı ve alternatif sayısı değiştirilerek duyarlılık analizi yapılıp bu değişmelerin sonuçları nasıl etkilediği gözlemlenebilir.

\section{Kaynakça}

Akyüz, G. (2012). Bulanık VIKOR Yöntemi ile Tedarikçi Seçimi. Atatürk Üniversitesi, İktisadi ve İdari Bilimler Dergisi, 26 (1), 197-215.

Armaneri, Ö., Özdağoğlu, G. \& Yalçınkaya, Ö. (2010). An Integrated Decision Support Approach for Project Investors in Risky and Uncertain Environments. Journal of Computational and Applied Mathematics, 234, 2530-2542.

Ayan Yakıcı, T. ve Perçin, S. (2012). AR-GE Projelerinin Seçiminde Grup Kararına Dayalı Bulanık Karar Verme Yaklaşımı. Atatürk Üniversitesi, İktisadi ve İdari Bilimler Fakültesi, 26 (2), 237-255.

Büyüközkan, G., \& Çiftçi, G. (2012). A Combined Fuzzy AHP and Fuzzy TOPSIS Based Strategic Analysis of Electronic Service Quality in Healthcare Industry. Expert Systems with Applications, 39, 2341-2354. 
Carlsson, C., Fuller, R., Heikkila, M., \& Majender, P. (2007). A Fuzzy Approach to R\&D Project Portfolio Selection. International Journal of Approxiamate Reasoning, 44, 93-105.

Chen, C. (2000). Extensions of the TOPSIS for Group Decision Making under Fuzzy Fnvironment. Fuzzy Sets and Systems, 114, 1-9.

Chen, T.C., Ching-Torng L., \& Huang, S.F., (2006). A Fuzzy Approach for Supplier Evaluation and Selection in Supply Chain Management. International Journal of Production Economics, 102, 289-301.

Chen, L.Y., \& Wang, T.C. (2009). Optimizing Partners' Choice in IS/IT Outsourcing Projects: The Strategic Decision of Fuzzy VIKOR. International Journal of Production Economics, 120, 233-242.

Chou, T., Chou, S., \& Tzeng, G. (2006). Evaluating IT/ IS investments: A Fuzzy Multi-criteria Decision Model Approach. European Journal of Operationa Research, 173, 1026-1046.

El-Santawy, M.F. (2012). A VIKOR Method for Solving Personnel Training Selection Problem. International Journal of Computing Science, 1 (2), 9-12

Ersoylu, İ. (2011). Bulanik VIKOR ve Bulanik AHP Yöntemleri ile Performans Ölçümü. Yayınlanmamıș Yüksek Lisans Tezi, Hava Harp Okulu, Havacilık ve Uzay Teknolojileri Enstitüsü.

Fasanghari, M., Amalnick, M. S., Chaharsooghi, S. K., \& Franz, I. S. (2011). The Fuzzy Evaluation of the ICT Projects in Strategic Environment (Case Study : Iran Telecommunication Research Center). International Journal of Information Technology \& Decision Making, 10 (5), 873-890.

Fishburn, P. C. (1967). Methods of Additive Utilities. Management Science, 13, 435-453

Fouladgar, M. M., Yazdani-Chamzini, A., Yakhchali, S. H., Ghasempourabadi, M. H., \& Badri, N. (2011). Project Portfolio Selection Using VIKOR Technique under Fuzzy Environment. $2^{\text {nd }}$ International Conference on Construction and Project Management, IPEDR, 15, 236-240
Hsieh, T.Y., Lu, S.T., \& Tzeng, G.H. (2004). Fuzzy MCDM Approach for Planning and Design Tenders Selection in Public Office Buildings. International Journal of Project Management, 22, 573-584

Hu, Y., Shu, W., \& Chu, L. (2009). Fuzzy Multicriteria Decision Making TOPSIS for Distribution Center Location Selection. International Conference on Networks Security, Wireless Communications and Trusted Computing.

Hwang, C.L., \& Yoon, K., (1981). Multiple Attributes Decision Making Methods and Applications. Springer, Berlin Heidelberg.

Lai, Y. ve Hwang C. (1996) Fuzzy Multiple Objective Decision Making: Methods and Applications. Lecture Notes in Economics and Mathematical Systems. Springer

Mohaghar, A., Fathi, M. R., Faghih, A., \& Turkayesh, M. M. (2012). An Integrated Approach of Fuzzy ANP and Fuzzy TOPSIS for R\&D Project Selection: A Case Study. Australian Journal of Basic and Applied Sciences, 6 (2), 66-75.

Opricovic, S. (1998). Multi-criteria Optimization of Civil Engineering Systems, Faculty of Civil Engineering, Belgrade

Opricovic, S., \& Tzeng, G. H. (2004). The Compromise Solution by MCDM methods: A Comparative Analysis of VIKOR and TOPSIS. European Journal of Operational Research, 15 (2), 445-455.

Opricovic, S., \& Tzeng, G. H. (2007). Extended VIKOR Method in Comparison with Outranking Methods. European Journal of Operational Research, 178 (2), 514-529.

Opricovic, S. (2011). Fuzzy VIKOR with an Application to Water Resources Planning. Expert Systems with Applications, 38, 12983-12990.

Poh, K. L., Ang, B. W., \& Bai, F. (2001). A Comparative Analysis of R\&D Project Evaluation Methods. $R \& D$ Management, 31, 63-75 
Rafiei, H. \& Rabbani, M. (2009). Project Selection Using Fuzzy Group Analytic Network Process. World Academiy of Science, Engineering and Technology, 58, 457-461.

Ravanshadnia, M., Rajaie, H., \& Abbasian, H., R. (2010). Hybrid Fuzzy MADM Project-Selection Model for Diversified Construction Companies. Can. J. Civ. Eng., 37, 1082-1093

Rouendegh, B. D., \& Erol, S. (2012). Selecting the Best Prject Using the Fuzzy ELECTRE Method. Mathematical Problems in Engineering, 4-13.

Saaty, T. L. (1980). The Analytic Hiearchy Process. New York, McGraw-Hill

Saaty, T.L. (1996). Decision Making with Dependence and Feedback: The Analytic Network Process. Pittsburgh: RWS Publications.

Salehi, M., \& Tavakkoli-Moghaddam, R. (2008). Project Selection by Using a Fuzzy TOPSIS Technique. World Academy of Science, Engineering and Technology, 40, 85-90.

Saraçoğlu, B. Ö. ve Odabaşı, A. Y. (2011). "Büyük Yatırım Analizlerinde Yeni Genel Bir Yöntem". itüdergisi/d mühendislik, 10 ( 1), 81-92
Tolga, A. Ç. (2008). Fuzzy multicriteria R\&D Project Selection with a Real Options Valuation Model. Journal of Intelligent \& Fuzzy Systems, 19, 359-371.

Tolga, A. Ç. ve Kahraman, C. (2009). Ar-Ge Projelerinin Gerçek Opsiyon Değerleme Bütünleşik Bulanık Çok Ölçütlü Modelle Seçimi. itüdergisi/d mühendislik, 8 (4), 95-106.

Triantaphyllou, E., 2000. Multi-Criteria Decision Making Methods: A Comparative Study. Kluwer Academic Publishers, Dordrecht.

Wang, J., \& Hwang, W. (2007). A Fuzzy Set Approach for R\&D Portfolio Selection Using a Real Options Valuation Model. Omega, 35, 247-257.

Zadeh, L.A. (1965), Fuzzy Sets. Information and Control 8, 338-383

Zadeh, L.A. (1975). The Concept of Linguistic Variable and its Application to Approximate Reasoning 1. Information Sciences 8, 199-249

Zingil, T. (2009). Supplier Selection Using TOPSIS and VIKOR Under Fuzzy Environment. Unpublished Master's Thesis, University of Bahcesehir. 